\title{
Zero-fluoro atrial flutter ablation in a pregnant woman with a pacemaker
}

\author{
Keiko Shimamoto (D) , ${ }^{1}$ Kenichiro Yamagata (D) , ${ }^{1}$ Chizuko Kamiya, ${ }^{2}$ \\ Kengo Fukushima Kusano ${ }^{1}$
}

'Department of Cardiovascular Medicine, National Cerebral and Cardiovascular Center, Suita, Japan

${ }^{2}$ Department of Perinatology and Obstetrics, National Cerebral and Cardiovascular Center, Suita, Japan

Correspondence to Dr Kenichiro Yamagata; look.tky@ncvc.go.jp

Accepted 26 February 2021

Check for updates

(c) BMJ Publishing Group Limited 2021. No commercial re-use. See rights and permissions. Published by BMJ.

To cite: Shimamoto $\mathrm{K}$, Yamagata K, Kamiya C et al. BMJ Case Rep

2021:14:e240671.

doi:10.1136/bcr-2020

240671

\section{DESCRIPTION}

A 33-year-old woman at 17 weeks of gestation who had a single-chamber atrial pacemaker implanted (figure 1A) owing to sick sinus syndrome presented with a typical atrial flutter (AFL) (figure 1B) and decreased cardiac contractility. She had heart failure during a previous pregnancy because of AFL with a 2:1 ventricular conduction despite receiving multiple antiarrhythmic medications during hospitalisation. Therefore, cavo-tricuspid isthmus (CTI) ablation was chosen rather than antiarrhythmic medications. Cardiotocography was used to monitor the fetal heart rate intraoperatively. Without sedation, an intracardiac echocardiography (ICE) catheter was inserted via the left femoral vein. After confirming that the pacemaker lead was placed in the right atrial appendage (figure 1C, white arrow), the decapolar catheter was inserted into the coronary sinus (video 1 ) and the ablation catheter was placed at the CTI. We confirmed visually using ICE combined with a threedimensional (3D) electroanatomical mapping system (EnSite NavX, Abbott, IL, USA) that both catheters did not interfere with the atrial pacemaker lead (figure 1D-F). Bidirectional CTI block was confirmed after 12 radiofrequency applications without using fluoroscopy during the entire procedure. No complications occurred in the patient or the fetus, and the pacemaker lead remained intact. The patient showed no signs of heart failure during delivery at 37 weeks of gestation or during the peripartum period. Her left-ventricular ejection fraction improved from 34\% to $50 \%$ after AFL termination, and there was no recurrence on 6 months of follow-up.

The incidence of AFL or atrial fibrillation during pregnancy in patients with heart diseases is low $(1.3 \%)$, as evidenced by a large registry study. ${ }^{1}$ These arrhythmias increase the risk of maternal mortality; therefore, arrhythmia control is crucial in these patients. Control of heart rate is recommended as the first-line therapy, but this had failed in this patient during a previous pregnancy.

Catheter ablation is an alternative therapy and is a class IIA indication in pregnant patients, especially for those in their second trimester and those who have drug-refractory or poorly tolerated supraventricular tachycardia. ${ }^{2}$ Fetal exposure to radiation during ablation occurs while inserting the electrode catheters from the groin to the heart under fluoroscopic guidance and indirectly as scattered radiation from the mother's thorax after the catheter is advanced into the heart. ${ }^{3}$ During conventional ablation procedures for supraventricular tachycardia in the second trimester, the conceptus is exposed to an estimated

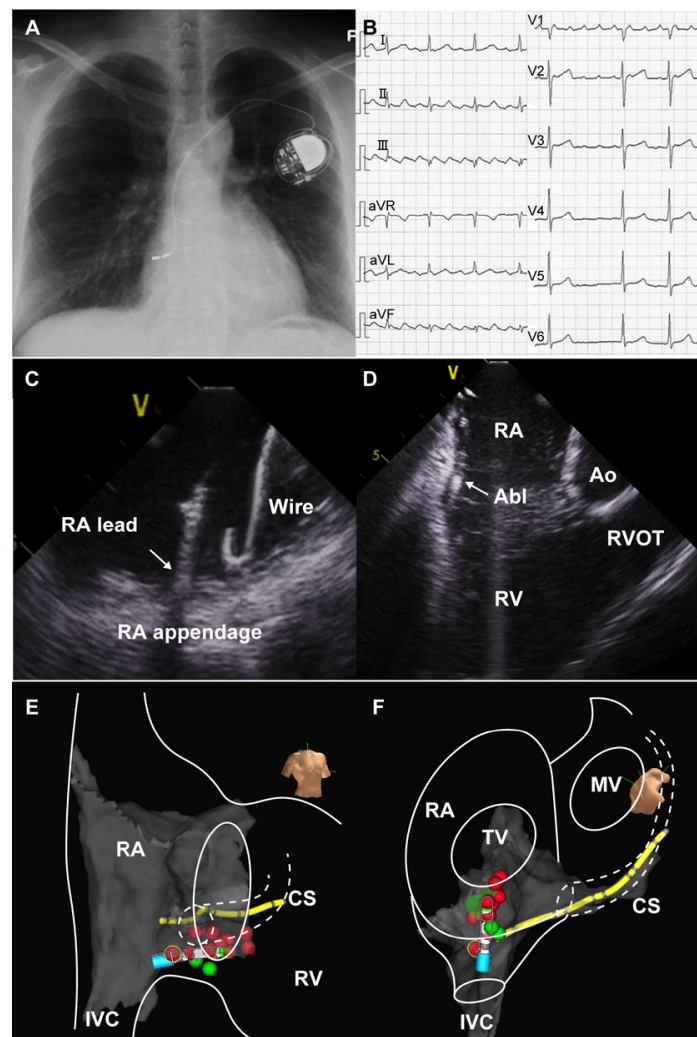

Figure 1 Patient's baseline examinations and findings during catheter ablation. (A) Chest radiograph shows the pacemaker lead in the patient's RA. (B) A 12 lead ECG shows a typical atrial flutter. (C) Intracardiac echocardiographic view of the atrial lead (white arrow) in the right atrial appendage (RA appendage) and the connecting wire. (D) Intracardiac echocardiographic view of the ablation catheter (Abl) placed on the patient's cavo-tricuspid isthmus during the ablation procedure. ( $E$ and F) Right oblique projection and the left anterior oblique-caudal projection of the three-dimensional electroanatomical map showing the ablation catheter on the patient's cavo-tricuspid line (the red dot indicates the ablation point) and the CS catheter (yellow) in the CS. $\mathrm{Ao}$, aorta; $\mathrm{CS}$, coronary sinus; IVC, inferior vena cava; MV, mitral valve; $\mathrm{RA}$, right atrium; $\mathrm{RV}$, right ventricle; $\mathrm{RVOT}$, right ventricular outflow tract; TV, tricuspid valve.

radiation dose of $300 \times 10^{-3} \mathrm{mGy}{ }^{3}$ Although this dose is within the safety margin of $100 \mathrm{mGy}$ for radiation-induced non-cancer health effects, there is no lower threshold for stochastic effects, including carcinogenesis. ${ }^{4}$ Therefore, a better approach is required to reduce radiation exposure to achieve the As Low As Reasonably Achievable principle. 


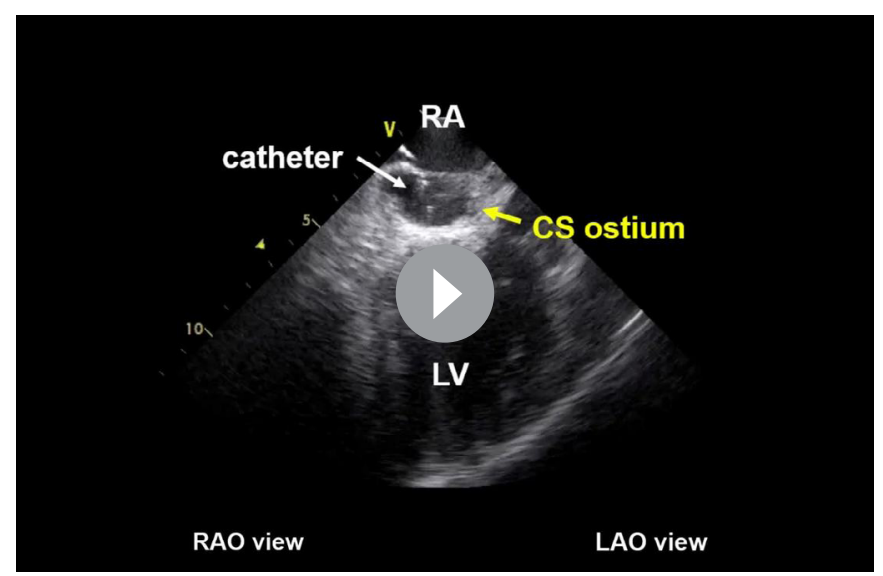

Video 1 The process of catheter insertion to the coronary sinus without fluoroscopy. The decapolar catheter is inserted through the inferior vena cava (IVC) into the right atrium (RA) under the guidance of a 3-dimensional electroanatomical mapping system. After confirming that the atrial potentials of the RA were recorded at the electrodes, the catheter is placed at the level of the ostium of the coronary sinus (CS), and the atrial and ventricular chambers are visualized using intracardiac echocardiography. Insertion of the catheter into the CS ensures that the electrode detects both atrial and ventricular potentials. MV: mitral valve, TV: tricuspid valve

\section{Patient's perspective}

I feel better after termination of the arrhythmias. It was not that difficult for me to lie still intraoperatively as the operation time was short.

\section{Learning points}

- Catheter ablation is a feasible treatment option for controlling supraventricular arrhythmias in pregnant patients.

- Radiation exposure should be minimised, especially during pregnancy.

- Zero-fluoro catheter ablation guided by a combination of intracardiac echocardiography and a three-dimensional electroanatomical mapping system is achievable and safe in patients with pacemakers.
Zero-fluoro ablation with a 3D electroanatomical mapping system is becoming a standard, straightforward procedure in such patients. However, reports on zero-fluoro ablations in patients with pacemaker leads are limited, possibly due to serious concerns associated with the risk of direct lead damage during radiofrequency application or pacemaker lead dislodgment during catheter manipulation. A previous prospective study on the effect of radiofrequency application on pacemaker leads focused on the critical requirements of keeping a certain distance from the tips of the leads and using guided fluoroscopic imaging to avoid interference when manipulating the ablation catheter. ${ }^{5}$ In the current case, we used ICE guidance instead of fluoroscopy to achieve similar results. In summary, zero-fluoro ablation guided by a combination of ICE and 3D electroanatomical mapping system along with careful catheter manipulation was feasible in a pregnant woman with cardiac pacemakers.

Correction notice This article has been corrected since it was first published Online. The missing video file is now included in the article.

Acknowledgements We would like to thank Editage for English language editing

Contributors $\mathrm{KS}$ and $\mathrm{KY}$ performed the procedure, collected and interpreted data, and wrote the manuscript with intellectual support from CK and KFK.

Funding The authors have not declared a specific grant for this research from any funding agency in the public, commercial or not-for-profit sectors.

Competing interests None declared.

Patient consent for publication Obtained.

Provenance and peer review Not commissioned; externally peer reviewed.

\section{ORCID iDs}

Keiko Shimamoto http://orcid.org/0000-0001-6296-150X Kenichiro Yamagata http://orcid.org/0000-0002-9571-7017

\section{REFERENCES}

1 Salam AM, Ertekin E, van Hagen IM, et al. Atrial Fibrillation or Flutter During Pregnancy in Patients With Structural Heart Disease: Data From the ROPAC (Registry on Pregnancy and Cardiac Disease). JACC Clin Electrophysio/ 2015;1:284-92.

2 Regitz-Zagrosek V, Roos-Hesselink JW, Bauersachs J, et al. 2018 ESC guidelines for the management of cardiovascular diseases during pregnancy. Eur Heart $\rfloor$ 2018;39:3165-241

3 Damilakis J, Theocharopoulos N, Perisinakis K, et al. Conceptus radiation dose and risk from cardiac catheter ablation procedures. Circulation 2001;104:893-7.

4 Brent RL, Bushberg JT, Linet M. NCRP report No. 174. preconception and prenatal radiation exposure: health effects and protective guidance, 2013May: 351 (Recommendations of the National Council on Radiation Protection and Measurements, Bethesda, MD, USA).

5 Newby KH, Zimerman L, Wharton JM, et al. Radiofrequency ablation of atrial flutter and atrial tachycardias in patients with permanent indwelling catheters. Pacing Clin Electrophysiol 1996;19:1612-7

Copyright 2021 BMJ Publishing Group. All rights reserved. For permission to reuse any of this content visit

https://www.bmj.com/company/products-services/rights-and-licensing/permissions/

BMJ Case Report Fellows may re-use this article for personal use and teaching without any further permission.

Become a Fellow of BMJ Case Reports today and you can:

- Submit as many cases as you like

- Enjoy fast sympathetic peer review and rapid publication of accepted articles

- Access all the published articles

- Re-use any of the published material for personal use and teaching without further permission

Customer Service

If you have any further queries about your subscription, please contact our customer services team on +44 (0) 2071111105 or via email at support@bmj.com.

Visit casereports.bmj.com for more articles like this and to become a Fellow 